Vol. 7(2), pp. 11-17, March, 2015

DOI: $10.5897 / J E N 2015.0116$

Article Number: 79BA3C 651630

ISSN 2006-9855

Copyright (C) 2015

Journal of Entomology and Nematology

Author(s) retain the copyright of this article

http://www.academicjournals.org/JEN

\title{
Isolation and identification of fungal growth on Tribolium castaneum in stored wheat flour
}

\author{
Bosly, H. A. and El-Banna O. M. \\ Department of Biology, Faculty of Science, Jazan University, Jazan, Saudi Arabia. \\ Received 31 January, 2015; Accepted 2 March, 2015
}

\begin{abstract}
Stored wheat flour samples purchased from Jazan local markets in Saudi Arabia were checked for the presence of pests, insect and fungal species. The insects existing in the flour were separated and identified as red flour beetle Tribolium castaneum and from 60 individuals (dead bodies) inspected, 17 individuals exhibited abnormal deformation, decomposition and or superficial fungal growths. Incubation of the dead insects' bodies resulted in emergence of fungal growth on the surface of these bodies. Nine fungal species that belonged to eight fungal genera were isolated. Results indicate that Beauveria bassiana and Verticillium lecanii were the most dominant fungi among those isolated from $T$. castaneum growing in flour followed by Sporothrix sp., Hirsutella versicolor, Granulomanus sp., modern Rhizoctonia solani, Moelleriella sp., Aspergillus fumigatus and A. flavus.
\end{abstract}

Key words: Stored wheat flour, Tribolium castaneum, fungi, Jazan, Saudi Arabia.

\section{INTRODUCTION}

Saudi Arabia is a sub-tropical country, with a warm climate that favors the multiplication of microorganisms and destructive pests of stored products (Tirado et al., 2010). Tribolium castaneum is one of the most destructive beetle pests of stored products and a major pest of cereals worldwide especially in tropical and sub-tropical regions (Islam and Talukder, 2005). Damage to agricultural crops both in the field and during harvest and storage due to fungi is also very considerable as it reaches billions of dollars around the world (Kendrick, 1992). Insects, nematodes, fungi, and microorganisms constantly compete with humans for these commodities. In a closer look, interactions of these organisms might be more complicated. The stored wheat flour is subjected to invasion with the red flour beetle, Tribolium castaneum
(Wakil et al., 2003).

Some insect species, including many pests, are particularly susceptible to infection by naturally occurring, insect-pathogenic fungi. These fungi are very specific to insects, often to particular species, and do not infect animals or plants. They are generally safe for the environment and thus considered to be among the most promising alternatives to chemical-based insect control (Sahayaraj and Tomson, 2010). Fungal growth favored by moist conditions but fungi also have resistant stages that maintain infection potential under dry conditions. Fungi have considerable epizootic potential and can spread quickly through an insect population and cause its collapse (Hoffmann and Frodsham 1993; Maria et al., 2006; Sahayaraj and Tomson, 2010). Primary hosts of

${ }^{\star}$ Corresponding author. E mail: dr 2009 bosly@hotmail.com.

.Author(s) agree that this article remain permanently open access under the terms of the Creative Commons Attribution License $\underline{4.0 \text { International License }}$ 
the majority of these fungi are aphids, whiteflies, leafhoppers, flies, beetles, caterpillars, thrips, mites and some beetle larvae.

The most recorded entomopathogenic fungi species were, Beauvaria bassiana, Asperigillus, Penicillium, Metarrhizium, Tolypocladium, Isaria, Lecanicillium Aschersoniabadia, Aachersonia marginata, Aschersonia samoensis, A. oxystoma, A. placenta, A. confluens, Hypocrellasia mensis, Moelleriella raciborskii, Hypocrella calendulina, Paecilomyces cinnamomeus, Conoideocrella tenuis and Verticillium spp. (Lord, 2001; Shah and Pell, 2003). Lawrence and Milner (1996) and Shah and Pell (2003) indicated that Ophiocordyceps unilateralis, $O$. myrmecophila, Torrubiella sp., Isaria sp., Paecilomyces lilacinus, Isariatenuipes, Gibellula pulchra, Nomuraeaa typicola, Hirsutella formicarum, Metarhizium sp., Akanthomyces pistillariiformis and Hirsutella citriformis are entomopathogenic fungi applied as biocontrol agents. In addition to the previously mentioned fungi, Akanthomyces, Aschersonia, Beauveria, Conoideocrella, Cordyceps, Gibellula, Hirsutella, Hymenostilbe, Hypocrella, Isaria, Metarhizium, Moelleriella, Nomuraea, Ophiocordyceps, Paecilomyces, Torrubiella and Verticillium are entomopathogenic fungi and associated with many insects.

The goal of this work was to isolate and identify fungi naturally associated with $T$. castaneum and to study the effect of these fungi on their insect hosts and to keep them as stock for further research concerning biological control application.

\section{MATERIALS AND METHODS}

\section{Source of wheat Flour samples}

Twenty-four wheat flour samples in paper packets of $1 \mathrm{Kg}$ each purchased from Jazan local markets in Saudi Arabia were stored at room temperature $\left(22-35^{\circ} \mathrm{C}\right)$ and $65-68 \%$ relative humidity for two years. The mean temperature and relative humidity were as follows; January daytime highest temperature was $88^{\circ} \mathrm{F}\left(31^{\circ} \mathrm{C}\right)$ and lowest was $71^{\circ} \mathrm{F}\left(22^{\circ} \mathrm{C}\right)$, while July had average daytime highest temperature of $104^{\circ} \mathrm{F}\left(40^{\circ} \mathrm{C}\right)$ and lowest of $86^{\circ} \mathrm{F}\left(30^{\circ} \mathrm{C}\right)$ (Bosly and Kawanna, 2014). At the end of the storage period, the flour was characterized with yellowish color and undesirable odors. The flour were checked for the presence of pests, insects and fungal species associated with or affecting them.

\section{Separation and identification of the affected insects}

The insects existing in the flour were separated and identified as Red flour beetle $T$. castaneum according to the key given by Hinton (1945) and Bousquet (1990).

\section{Isolation of fungi associated with the separated insects}

Isolation of fungi associated with the separated $T$. castaneum was done in three successive stages as follows:

\section{Separation of the affected insects}

The dead bodies of $T$. castaneum (60 individuals) separated from the flour using a silk sieve, were cleaned by the aid of camel hairbrush to remove the flour. The insect's dead bodies were inspected by the binuclear for any deformations or decomposition. The individuals exhibited abnormal deformation, decomposition and or superficial fungal growths were photographed by a (zoom in) digital camera.

\section{Incubation of the candidate insects}

The individuals of $T$. castaneum that showed decomposition or fungal growths were incubated to allow the emergence of fungal growth from both outside and inside the affected insects. For incubation, plastic Petri dishes $(9 \mathrm{~cm})$ each containing sterilized filter paper (Whatman No1) were used. Sterilized glass slide was fixed above the filter paper. Using sterilized fine tip forceps, the individuals were transferred and put above the slide. Two individuals were put on each slide. The filter papers were kept wet by dispensing $1 \mathrm{ml}$ of sterilized distilled water according to Dhingra and Sinclair (1985). The dishes were covered and sealed using para film and incubated at $25 \pm 2^{\circ} \mathrm{C}$ for 7 days. After elapse of the incubation period, insects were checked for emergence of fungal growth by the binuclear and the individuals that the fungi observed on their surfaces were labeled and used in the isolation experiment.

\section{Isolation and identification of the emerged fungi}

For isolation of the emerged fungi associated with the insects, Petri dishes $(9 \mathrm{~cm})$ containing PDA medium were used. Aseptically, small part of the fungal growth was taken from the surface of the insect body using a sterilized needle and transferred onto the surface of PDA medium in Petri dish. The dishes were labeled, sealed with parafilm and incubated at $25 \pm 2^{\circ} \mathrm{C}$. The dishes were checked for fungal growth after 3 and 7 days. The emerged fungi were picked-up and transferred to new PDA medium plates, purified and identified following keys given by Ainsworth (1971), Ellis (1971 and 1976), Barnett and Hunter (1972), Domsch et al. (1993)and Gadd et al. (2006). Frequency of each identified fungus was calculated according to the following equation:

Frequency percentage $=\frac{\text { Number of fungal colonies for each fungusX } 100}{\text { Total number of fungal colonies for the isolated fungi }}$

\section{Light microscope examination}

To identify the emerged fungi, slides from cultures of any of the previously mentioned fungi grown on the PDA medium for 7 days were prepared, fixed, stained with lacto phenol-cotton blue and examined by light microscope (ModelZeizz AX10) and photographs were captured using AxioCamICc1 using the program (Axiovission4.8.2-06-2010). Stock cultures on PDA under paraffin oil were kept in a refrigerator at $5-10^{\circ} \mathrm{C}$ and sub-cultured onto fresh medium every 2-3 weeks. These will be the potential biological materials for further research and application.

\section{RESULTS}

\section{Separation and identification of the affected insects}

The apparently healthy red flour beetle $T$. castaneum is 


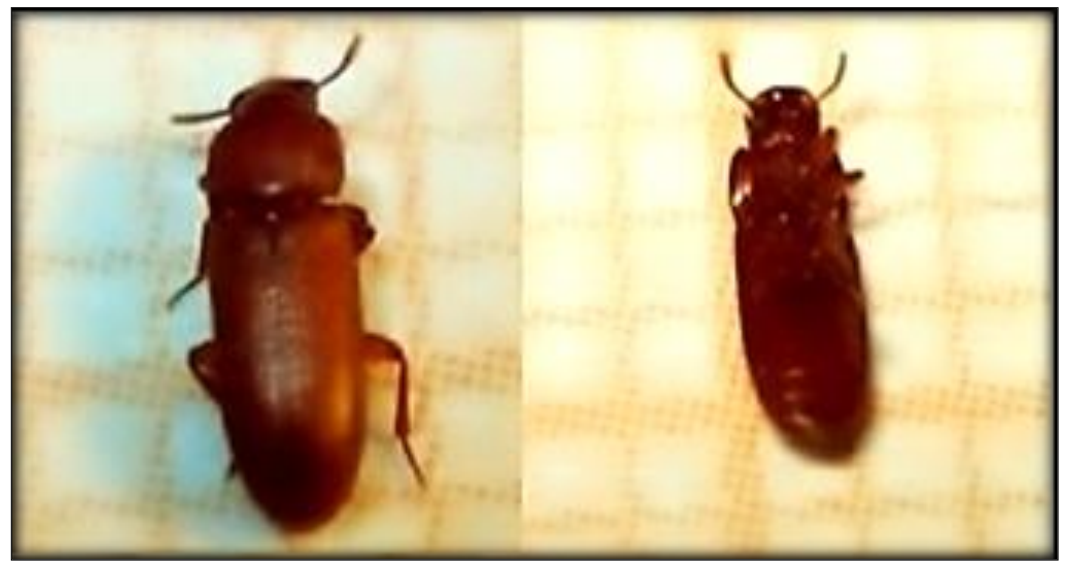

Figure 1. Photograph shows dorsal (left) and ventral (right) sides of the isolated non-infected $T$. castaneum.

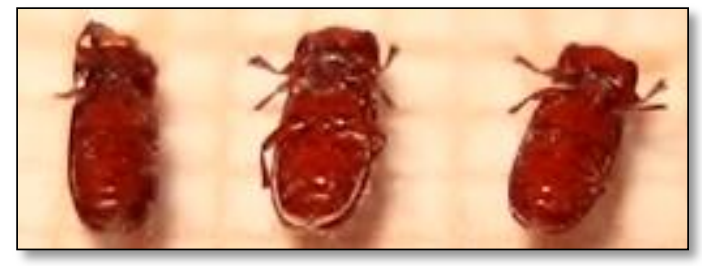

Figure 2. Photograph shows ventral side of $T$. castaneum at the beginning of infection by Verticilliumlecanii.

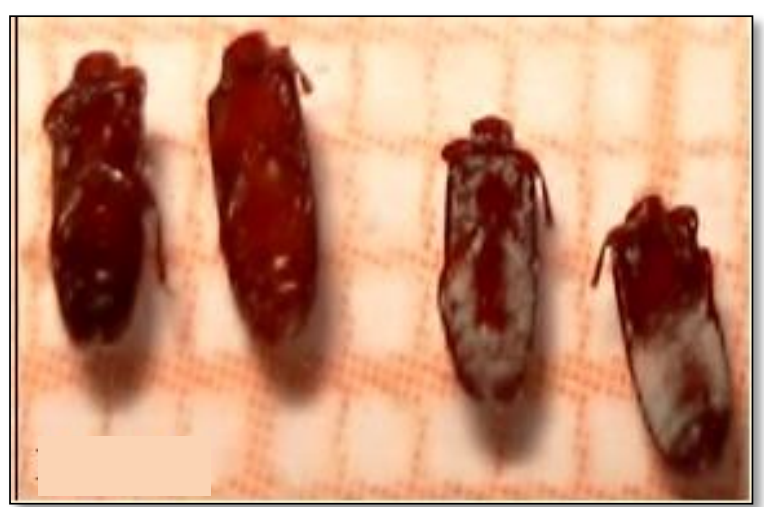

Figure 3. Different degrees of infection and colonization with Beauveriabassiana.

represented in Figure 1. About 60 insect dead bodies of the $T$. castaneum checked for the different degrees of degeneration were separated from the stored wheat flour, inspected and photographed. The insects exhibited various morphological deformations as showed in Figures 2, 3, 4 and 5 . The most characteristic deformation was the separa-

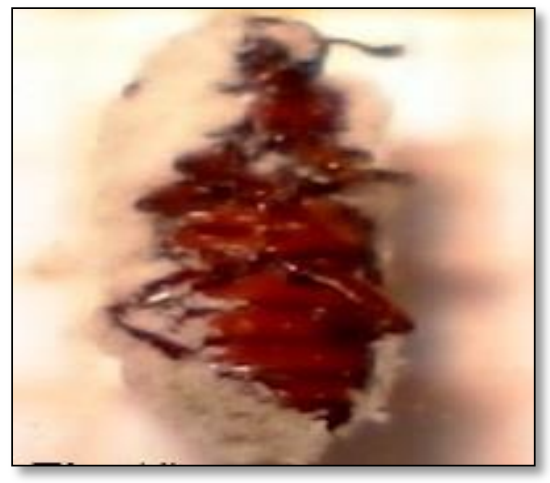

Figure 4. Photograph shows that the body of T.castaneumis already occupied by Beauveriabassiana.

tion of the insect head (Figure 6), decom-position of their wings (Figure 7), legs (Figure 8) and the abdomen (Figure 9). Some parts of the insects dead bodies were covered with colored fungal growths that ranged from olive green, white, grey, brown to black. The fungal infection ranged from distributed colonies on the insect body (Figure 2) or parts of it covered with the fungal growth (Figures 4, 5 and 7).

\section{Isolation and identification of the fungi associated with the separated insects}

Isolation from the candidate insect samples showed emergence of fungal growths by incubation which resulted in isolation of nine fungal species belonging to eight fungal genera (Table 1). The fungi isolated were purified and identified to the generic and/or the species level according to their morphological characteristics. 


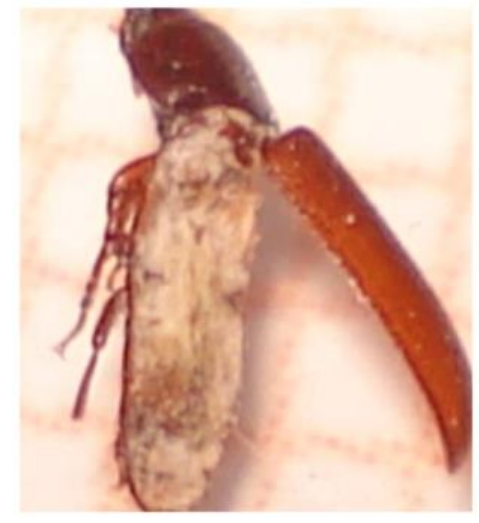

Figure 5. Abdomen completely colonized by Hirsutellaversicolor.
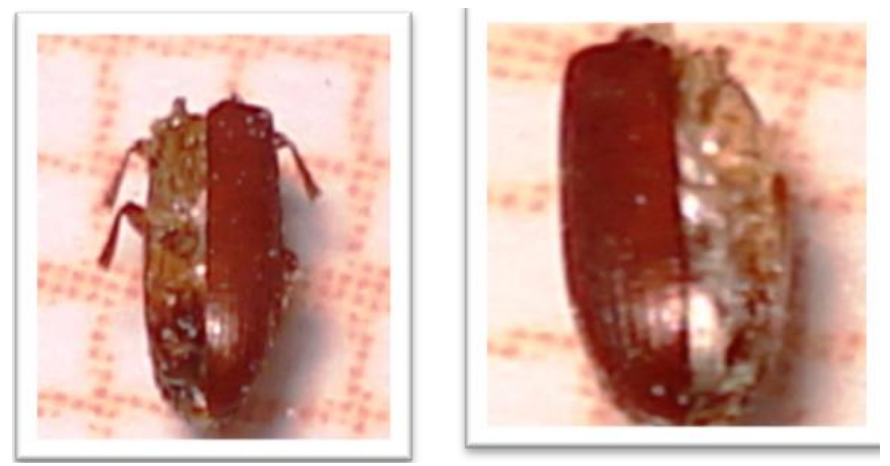

Figure 6. Photograph shows that the half of the dorsal $T$. castaneum decomposed and the head removed as a result of infection by Aspergillus flavus

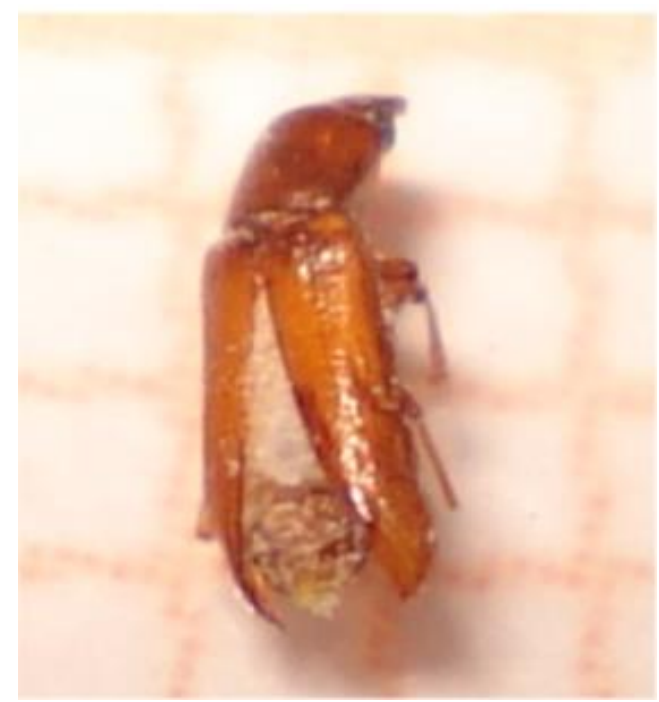

Figure 7. T. castaneum infected with Rhizoctonia solani.

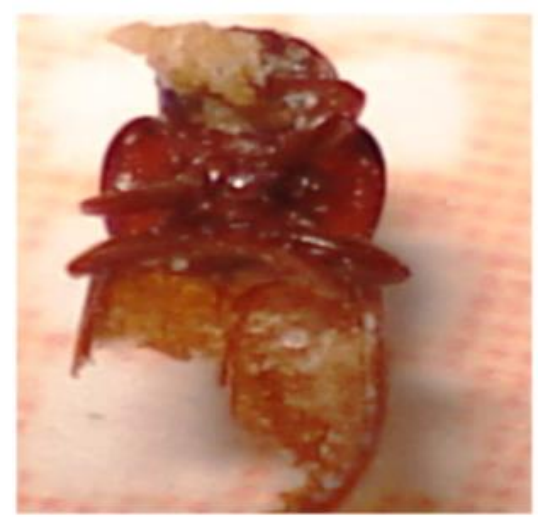

Figure 8. Photograph showing the decomposition of the lower part of the abdomen and the fungal growth of Sporothrix spp. that covers the frontal mouth parts.

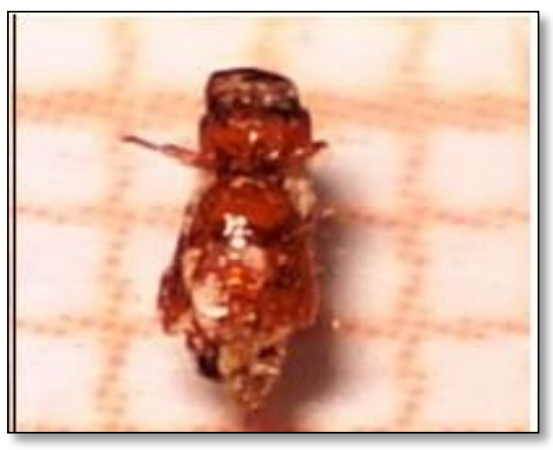

Figure 9. Decomposition of the abdomen and the $T$. castaneum dead body colonized by the fungal growth.

Results indicate that $B$. bassiana and $V$. lecanii were the most dominant fungi among those isolated from red flour beetle of wheat flour samples collected from Jazan showing 28.1 and $26.6 \%$, respectively, followed by Sporothrix spp. (14.1\%), Hirsutella versicolor (9.4\%), Granulomanus sp. (6.2\%), modern Rhizoctonia solani and Moelleriella sp. (4.7\%), Aspergillus fumigatus and $A$. flavus $(3.1 \%)$.

\section{Light microscopy}

The morphological features of the isolated fungi were studied through examination of slides prepared from the fungal colonies obtained on PDA medium. The preparations were stained by lactophenol-cotton blue and examined by light microscope at magnification 40x. The photographs are represented in Figure 10. 
Table 1. Fungi isolated from T.castaneum samples by culturing on PDA medium and their frequencies.

\begin{tabular}{lcc}
\hline Isolated fungi & Number of fungal colonies & (\%) \\
\hline Aspergillus flavus & 2 & 3.1 \\
Aspergillus fumigates & 2 & 3.1 \\
Beauveria bassiana & 18 & 28.1 \\
Hirsutella versicolor & 6 & 9.4 \\
Modern Rhizoctonia solani & 3 & 4.7 \\
Granulomanus sp & 4 & 6.2 \\
Nomuraeacy lindrospora & 3 & 4.7 \\
Sporothrix spp & 9 & 14.1 \\
Verticillium lecanii & 17 & 26.6 \\
Total & 64 & 100 \\
\hline
\end{tabular}

$*$ Frequency percentage $=\frac{\text { Number of fungal colonies for each fungusX } 100}{\text { Total number of fungal colonies for the isolated fungi }}$

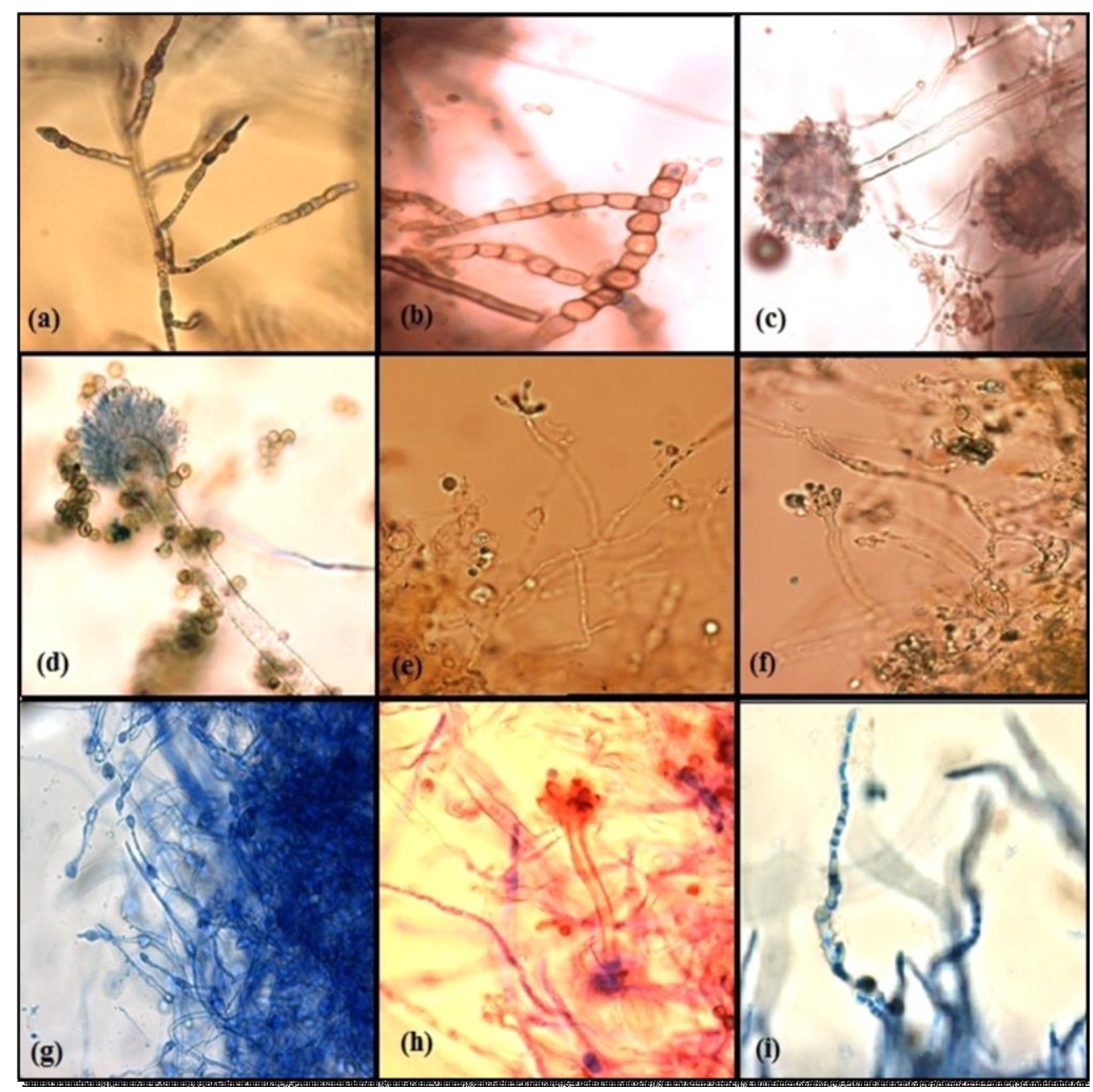

Figure 10. Light photographs $(40 \mathrm{X})$ showing the morphology of the fungi isolated from the candidate samples of Tribolium castaneum stained with lacto phenol-cotton blue: Verticillium lecanii (a); modern Rhizoctonia solani (b); Aspergillus flavus (c); Aspergillus fumigatus (d); Beauveria bassiana (e); Nomuraeacy lindrospora (f); Hirsutella versicolor (g); Sporothrix sp. (h) and Granulomanus sp. (i) 


\section{DISCUSSION}

Several studies confirmed the development and survival of $T$. castaneum in wheat flour (Khattak and Shafique, 1986; Shafique et al., 2006; Bosly and Kawanna, 2014). Infestation by insects encourages growth of fungi including those that produce mycotoxins, and results in contamination of commodities with insect bodies and waste products etc. The diversity and distribution of entomopathogenic fungal species depends on environmental conditions, diversity of insect species and their hosts. Dispersal of the fungus probably played an important role in the coevolution with its insect host and the co-evolution of the insect with its plant host (Chaverri et al., 2005). The high moisture and diversified and plentiful insects in tropical countries, especially those like our country (KSA) provide ideal conditions for the entomopathogenic fungi to develop as stated in Gadd et al. (2006). Previously, Shah and Pell (2003) indicated that the dead insect's body infected with an entomopathogenic fungi may be firm and "cheese-like" or an empty shell, often but not always with cream, green, red, or brown fungal growth, either enveloping the body or emerging from joints and body segments. Incubation of the candidate insects for 7 days at $25 \pm 2^{\circ} \mathrm{C}$ resulted in emergence of fungal growths on the surface of some incubated insects dead bodies. On the other hand, the rest of the incubated insects still clean even after prolonged incubation period to 14 days. Gabartya et al. (2014) described that $B$. bassiana and $M$. anisopliae are entomopathogenic and their infection begins when conidia (asexual spores, the seeds of a fungus) attach to insect's cuticle, the spores germinate and penetrate the insect's skin and enter the host. Once the fungus penetrates the host it produces toxins that overcome the insect immune system and the hyphae penetrate through the cuticle to the outside and cause white (B. bassiana) or green $(M$. anisopliae) sporulation on the insect's body. The obtained results about those fungi indicate that invading insects occurred by penetrating their cuticle or "skin." Once inside the insect, the fungus rapidly multiplies throughout the body. Death is caused by tissue destruction and, occasionally, by toxins produced by the fungus. The fungus frequently emerges from the insect's body to produce spores that, when spread by contact with other insects, can spread infection (Moino et al., 2002). Another explanation is the fungi secondary metabolites that increase the chance of insect death (Fan et al., 2013). The previously mentioned fungi have the ability to decompose cuticle layer to be able to penetrate the insect body and colonize it leading to death of these insects. The fungi act through the insect integument in several ways. Long chain hydrocarbons help in or play an important role in initial attachment of the entomopathogenic fungal spores to cuticle given that such dry phialocondia attach in nonspecific manner through hydrophobic interaction (Lord, 2001 and 2009; Shah and Pell, 2003). The chemical, biological or physical treatments for controlling the insects during storage may contribute towards reducing spread of fungal spores within the storage system (Huang et al., 1997; Athanassiou et al., 2008; Brijwani et al., 2010; Mohale et al., 2010; Beckett, 2011; Villers, 2014).

\section{Conclusion}

The natural death of the insects separated from the stored wheat flour gave us the idea of this investigation and the further studies of biological control of the red wheat flour $T$. castaneum. The fungi were isolated from insects naturally exhibiting different degrees of deformation, decomposition and superficial fungal growth. The more destructive fungal genera that is $B$. bassiana, $H$. versicolor, Sporothrix sp. and $V$. lecanii preserved for further study which will concern biological control of $T$. castaneum

It can be also be concluded that, storage of wheat flour under Jazan conditions which is characterized by high temperature and humidity resulted in the presence of $T$. castaneum. Moreover abnormal deformation, decomposetion and or superficial fungal growths flour should be stored in conditions to prevent the flour from attracting insects and fungi to avoid the loss of flour and the health damage resulting from the usage.

\section{ACKNOWLEDGMENT}

The authors would like to thank the Fungi Research Department, Plant Pathology Institute, Agriculture Research Center (ARC), Giza, Egypt for the identification of the isolated fungi.

\section{Conflict of interest}

The authors declared no conflict of interest.

\section{REFERENCES}

Ainsworth GC (1971). Ainsworth and Bisby's Dictionary of the Fungi. Sixth Edition Farnham Royal, Commonwealth Agricultural Bureaux [for the] Commonwealth Mycological Institute. ISBN-0851980759.

Athanassiou CG, Kavallieratos NG, Yiatilis AE, Vayias BJ, Mavrotas CS, Tomanović Z (2008). Influence of temperature and humidity on the efficacy of spinosad against four stored-grain beetle species. J. Insect Sci. 8(60): 1-9. http://dx.doi.org/10.1673/031.008.6001

Barnett HL, Hunter BB (1972). Illustrated Genera of Imperfect fungi. 3rd edition Burgess Publishing Co. USA.

Beckett SJ (2011). Insect and mite control by manipulating temperature and moisture before and during chemical-free storage J. Stored Prod. Res. 47: 284-292. http://dx.doi.org/10.1016/j.jspr.2011.08.002

Bosly HA, Kawanna MA (2014).Fungi species and red flour beetle in stored wheat flour under jazan region conditions. Toxicol. Health 30(4): 304-310. http://dx.doi.org/10.1177/0748233712457449

Bousquet $Y$ (1990). Beetles Associated with Stored Products in Canada: An Identification Guide, 240p. Agriculture Canada 
Publication 1837, Canada.

Brijwani M, Subramanyam B, Flinn PW, Langemeier MR (2010) Structural heat treatments against Triboliumcastaneum (Herbst) (Coleoptera: Tenebrionidae): effect of flour depth, life stage and floor. Paper presented at: Proceedings of the 10th International Working Conference on Stored Products Protection June 27 - July 2, Estoril, Portugal. pp. 622-627.

Chaverri P, Bischoff JF, Evans HC, Hodge KT (2005). Regiocrella, a new entomopathogenic genus with a pycnidialanamorph and its phylogenetic placement in the Clavicipitaceae. Mycologia 97(6): 1225-1237. http://dx.doi.org/10.3852/mycologia.97.6.1225

Dhingra OD, Sinclair JB (1985). Basic Plant Pathology Methods. CRC Press, Inc Boca Raton. Florida. USA.

Domsch KH, Gams W, Anderson TH (1993). Compendium of soil fungi. IHW-Verlag, Eching, Germany.

Ellis MB (1971). DematiaceousHyphomycetes. Commonwealth Mycological Institute. Kew, Surrey, England.

Ellis MB (1976). More DematiaceousHyphomycetes. Commonwealth Mycological Institute. Kew, Surrey, England.

Fan J, Xie Y, Xue J, Liud R (2013). The Effect of Beauveriabrongniartii and its Secondary Metabolites on the Detoxification Enzymes of the Pine Caterpillar, Dendrolimustabulaeformis. J. Insect Sci. 13:44. http://dx.doi.org/10.1673/031.013.4401

Gabartya A, Salema HM, Foudab MA, Abasb AA, Ibrahimc AA (2014). Pathogencity induced by the entomopathogenic fungi Beauveriabassiana and Metarhiziumanisopliae in Agrotisipsilon (Hufn.). J. Radiation Res. Appl. Sci. 7(1):95-100. http://dx.doi.org/10.1016/j.jrras.2013.12.004

Gadd GM, van West P, Robson GD (2006). Exploitation of Fungi. Cambridge: Cambridge University Press.

Hinton HE (1945). A monograph of the beetles associated with stored products- Volume 1. British Museum (Natural History), London. 443p

Hoffmann MP, Frodsham AC (1993). Natural Enemies of Vegetable Insect Pests. Cooperative Extension, Cornell University, Ithaca, NY. $63 \mathrm{p}$.

Huang Y, Tan JMW, Kini RM, Ho SH (1997) Toxic and antifeedant action of nutmeg oil against Triboliumcastaneum (Herbst) and SitophiluszeamaisMotsch. J. Stored Prod. Res. 33(4): 289-298. http://dx.doi.org/10.1016/S0022-474X(97)00009-X

Islam S, Talukder FA (2005). Toxic and residual effects of Azadirachtaindica, Tageteserecta and Cynodondactylon seed extracts and leaf powders towards Triboliumcastaneum. J. Plant Dis. Protect.112 (6):594-601.

Kendrick B (1992). The Fifth Kingdom, Second Edition 1992. Focus Texts, Focus Information Group, Inc., PO Box 369, Newburyport, MA 01950. ISBN 0941051285.
Khattak SUK, Shafique M (1986). Varietal susceptibility of ten wheat cultivars flour to red flour beetle, Tribolium castaneum (Herbst) (Coleoptera:Tenebrionidae). Pak. J. Zool. 18:257-261.

Lawrence JF, Milner RJ (1996). Associations between arthropods and fungi. Fungi Aust. 1B:137-202.

Lord JC (2001). Desiccant dusts synergize the effect of Beauveriabassiana (Hyphomycetes: Moniliales) on stored-grain beetles. J. Econ. Entomol. 94:367-372. http://dx.doi.org/10.1603/0022-0493-94.2.367

Maria PM, Christos GA, Nickolas GK, Yacoub AB, George NB (2006). Effectiveness of Metarhiziumanisopliae (Metschinkoff) Sorokin applied alone or in combination with diatomaceous earth against Tribolium confusum Du Val larvae: Influence of temperature, relative humidity and type of commodity. Crop Prot. 25:418-425. http://dx.doi.org/10.1016/j.cropro.2005.07.003

Mohale S, Allotey J, Saime BA (2010). Control of Tribolium confusum J Du Val. by diatomaceous earth (Protect-It[TM]) on stored groundnut (Arachishypogaea) and Aspergillus flavus linkspore dispersal. AJFAND. 10(6):2678-2694.

Moino JrA, Alves SB, Lopes RB, Oliveria PM, Neves J, Pereria RM, Vieira SA (2002). External development of the entomopathogenic fungi Beauveriabassiana and Metarhiziumanisopliaein the subterranean termite Heterotermestenuis. Sci. agric. (Piracicaba, Braz.). 59(2):267-273.

Sahayaraj K, Tomson M (2010). Impact of two pathogenic fungal crude metabolites on mortality, biology and enzymes of Dysdercusc ingulatus (Fab.) (Hemiptera: Pyrrhocoridae). J. Biopestic. 3:163-167.

Shafique M, Ahmad M, Chaudry MA (2006). Feeding Preference and Development of Tribolium castaneum (Herbst.) in Wheat Products. Pak. J. Zool. 38(1):27-31.

Shah PA, Pell JK (2003). Entomopathogenic fungi as biocontrol agents. Appl. Microbiol. Biotechnol. 61(5-6):413-423. http://dx.doi.org/10.1007/s00253-003-1240-8

Tirado MC, Clarke R, Jaykus LA, Mc Quatters-Gollop A, Frank JM (2010). Climate change and food safety: A review. Food Res. Int. 43(7):1745-1765. http://dx.doi.org/10.1016/j.foodres.2010.07.003

Villers $P$ (2014). Aflatoxins and safe storage. Front Microbiol. 5:158. http://dx.doi.org/10.3389/fmicb.2014.00158

Wakil W, Hassan M, Javed A, Anwar S (2003). Comparison of nutritional losses of insect infested wheat in laboratory and public storages. Pak. J. Arid Agric. 6:1-6. 